\title{
Survival of European Mouflon (Artiodactyla: Bovidae) in Hawai'i Based on Tooth Cementum Lines ${ }^{1}$
}

\author{
Steven C. Hess, ${ }^{2,7}$ Robert M. Stephens, ${ }^{3,6}$ Tommy L. Thompson, ${ }^{3}$ Raymond M. Danner ${ }^{4}$ \\ and Ben Kawakami $7 r^{5}$
}

\begin{abstract}
Reliable techniques for estimating age of ungulates are necessary to determine population parameters such as age structure and survival. Techniques that rely on dentition, horn, and facial patterns have limited utility for European mouflon sheep (Ovis gmelini musimon), but tooth cementum lines may offer a useful alternative. Cementum lines may not be reliable outside temperate regions, however, because lack of seasonality in diet may affect annulus formation. We evaluated the utility of tooth cementum lines for estimating age of mouflon in Hawai' $\mathrm{i}$ in comparison to dentition. Cementum lines were present in mouflon from Mauna Loa, island of Hawai'i, but were less distinct than in North American sheep. The two age-estimation methods provided similar estimates for individuals aged $\leq 3$ yr by dentition (the maximum age estimable by dentition), with exact matches in 51\% (18/35) of individuals, and an average difference of $0.8 \mathrm{yr}$ (range 0-4). Estimates of age from cementum lines were higher than those from dentition in 40\% (14/35) and lower in 9\% (3/35) of individuals. Discrepancies in age estimates between techniques and between paired tooth samples estimated by cementum lines were related to certainty categories assigned by the clarity of cementum lines, reinforcing the importance of collecting a sufficient number of samples to compensate for samples of lower quality, which in our experience, comprised approximately $22 \%$ of teeth. Cementum lines appear to provide relatively accurate age estimates for mouflon in Hawai $i$, allow estimating age beyond $3 \mathrm{yr}$, and they offer more precise estimates than tooth eruption patterns. After constructing an age distribution, we estimated annual survival with a log-linear model to be 0.596 (95\% CI 0.554-0.642) for this heavily controlled population.
\end{abstract}

European mouflon sheep, Ovis gmelini musimon (Pallas), from the Mediterranean islands have become invasive where they have

Pacific Science (2011), vol. 65, no. 1:59-67

doi: $10.2984 / 65.1 .059$

(C) 2011 by University of Hawai'i Press

All rights reserved

\footnotetext{
${ }^{1}$ This research was funded by the Natural Resources Preservation Program of the U.S. Geological Survey and the National Park Service, and the U.S. Geological Survey Invasive Species Program. Portions of this research were performed under Cooperative Agreement 3036 WS 0028 to the University of Hawai'i at Hilo. Any use of trade, product, or firm names in this publication is for descriptive purposes and does not imply endorsement by the U.S. Government. Manuscript accepted 22 April 2010.
}

been introduced to the Canary, Kerguélen, and Hawaiian archipelagos (Chapuis et al. 1994, Hess et al. 2006, Nogales et al. 2006).

\footnotetext{
${ }^{2}$ Pacific Island Ecosystems Research Center, U.S. Geological Survey, Kìlauea Field Station, P.O. Box 44, Hawai'i National Park, Hawai'i 96718.

${ }^{3}$ Hawai'i Cooperative Studies Unit, Pacific Aquaculture and Coastal Resources Center, University of Hawai' $i$ at Hilo, P.O. Box 44, Hawai'i National Park, Hawai'i 96718.

${ }^{4}$ Department of Biological Sciences, Virginia Polytechnic Institute and State University, 2119 Derring Hall, Blacksburg, Virginia 24061.

${ }^{5}$ U.S. National Park Service, Division of Resources Management, P.O. Box 52, Hawai'i National Park, Hawai'i 96718 .

${ }^{6}$ Department of Land and Natural Resources, Division of Forestry and Wildlife, 19 East Kāwili Street, Hilo, Hawai'i 96720.

${ }^{7}$ Corresponding author (e-mail: shess@usgs.gov).
} 
Mouflon were first introduced to the Hawaiian Islands in 1954 as a game species (Tomich 1986). The Kahuku mouflon population on Mauna Loa, Hawai'i Island, was founded by only 11 individuals between 1968 and 1974 (Hess et al. 2006). Although three separate mouflon populations have been established on the islands of Lāna'i and Hawai'i, to date there have been little data collected on age determination (O'Gara 1994) and no previous study of survival (Giffin 1982, Tomich 1986, Hess et al. 2006, Stephens et al. 2008).

Ungulate species that have been translocated between temperate and tropical regions of the world provide unique opportunities to compare how environmental conditions may affect aspects of population dynamics (Gaillard et al. 1998). Analyses of comparative population dynamics may be beneficial not only for predicting life history characteristics of ungulates that have the potential to become invasive but also for formulating effective strategies to control these species. Exploration of population parameters such as age structure and survival first requires reliable methods for age assessment (Eberhardt 1985). Methodological issues of age determination, however, may be confounded by environmental conditions.

Garel et al. $(2005,2006)$ found that field observations of horn and facial patterns were poor characteristics for discriminating age classes of adult mouflon in southern France, particularly for ewes. These patterns may also be affected by local environmental conditions as well as the genetic composition of the founding population. Tooth cementum patterns, however, provide an effective method for determining age in many mammal species (Laws 1952, Grue and Jensen 1979). Alternating wide light-colored cementum bands and thin dark-colored "cementum lines" are deposited yearly in many mammals (Grue and Jensen 1979). The cause of their formation is imprecisely known and may include both endogenous and exogenous controls. Endogenous control, such as hormone cycles, was supported for humans (Homo sapiens) (Wittwer-Backofen et al. 2004) and captive giraffes (Giraffa camelopardalis) (Spinage 1976), which deposited cementum lines annu- ally despite experiencing relatively constant environmental conditions. Exogenous control was reported by Lieberman (1993), who found that altering the physical composition and nutrition of food created cementum lines in captive goats (Capra hircus). The reliability of determining age using cementum needs further evaluation for species at latitudes $<36^{\circ}$ (Brokx 1972, Hackett et al. 1979), where weak seasonality in diet may reduce environmental effects on cementum deposition, causing indistinct cementum line formation or multiple lines per year (Mason 1984, Kay and Cant 1988, Lieberman 1993, Hamlin et al. 2000). Our objectives were to: (1) evaluate the utility of tooth cementum lines in comparison with dentition for estimating age in mouflon in Hawai' $i$; and (2) construct the age distribution and estimate annual survival of a mouflon population based on tooth cementum.

\section{Study Area}

Mouflon occupied two major vegetation types within the Kahuku Unit of Hawai'i Volcanoes National Park on the island of Hawai' $i$ (centered at approximately $19^{\circ} 18^{\prime} \mathrm{N}, 155^{\circ}$ $40^{\prime} \mathrm{W}$ ): improved pastures in degraded mesic montane forest between 600 and 1,600 m elevation on the southern ridge of Mauna Loa; and subalpine shrubland between 1,600 and 2,700 $\mathrm{m}$ on the southeastern flank of Mauna Loa. Mesic montane forest had been converted to open woodlands dominated by scattered tall-stature native 'ōbi'a (Metrosideros polymorpha) trees and, to a lesser extent, native koa (Acacia koa) trees, and highly modified pastures of primarily alien kikuyu grass (Pennisetum clandestinum) understory for cattle grazing. Higher-elevation areas were subalpine shrublands dominated by native ' $a{ }^{6} a l^{6} i$ (Dodonaea viscosa), 'ōbelo (Vaccinium spp.), pükiawe (Leptecophylla tameiameiae), a native bunchgrass (Deschampsia nubigena), and short-stature 'ōbi'a woodland. Strong climatic gradients within Kahuku are due to orographic effects over a broad range of elevation; however, mean annual precipitation from 1983 to 2008 at $1,570 \mathrm{~m}$ elevation was $975.2 \pm 341.3(\mathrm{SD}) \mathrm{mm}$, and greatest mean 
monthly rainfall occurred between November and January $(115.7 \mathrm{~mm})$. Months with the least precipitation were May and June (54.8 $\mathrm{mm})$. Mean annual minimum and maximum temperatures were approximately $9^{\circ} \mathrm{C}$ and $19^{\circ} \mathrm{C}$, respectively. Occasional frost occurred at higher elevations from December to February. The $209 \mathrm{~km}^{2}$ study area was inhabited by approximately 2,600 mouflon in November 2004 (Hess et al. 2006).

\section{MATERIALS AND METHODS}

\section{Data Collection}

We necropsied mouflon in compliance with University of Hawai'i IACUC Protocol 06043 during a directed volunteer ungulate control program in February-March 2007 and January-March 2008. We determined sex by examination of external genitalia and approximate age by eruption and wear patterns of lower incisors $\left(\mathrm{I}_{1-3}\right)$ and canines $\left(\mathrm{C}_{1}\right)$ based on criteria for domestic sheep $(O$. aries): Incisors and canines deciduous $=$ age $0 \mathrm{yr}$, Adult $\mathrm{I}_{1}=1 \mathrm{yr}$, Adult $\mathrm{I}_{2}=2 \mathrm{yr}$, Adult $\mathrm{I}_{3}=3 \mathrm{yr}$, Adult $\mathrm{C}_{1}=\geq 3$ yr (Montana Veterinary Research Laboratory 1936, Kammlade 1947). We sampled near the lambing season and therefore assumed animals with adult $\mathrm{I}_{3}$ to be $3 \mathrm{yr}$ old. Because dentition is typically complete by $3 \mathrm{yr}$, including premolars and molars, this method is incapable of precisely determining ages $>3$ yr (Montana Veterinary Research Laboratory 1936, Kammlade 1947). We extracted one $(n=44)$ or two $(n=5)$ lower $\mathrm{I}_{1}$ (total $n=54$ ) from animals postmortem using a dental elevator and pliers to examine cementum patterns (Matson 1981). To protect the periodontal membrane and root tip, samples were not cleaned or dried beyond ambient humidity. Each tooth was placed in a labeled paper envelope and stored at room temperature.

Matson's Laboratory (Milltown, Montana; www.MatsonsLab.com) processed tooth samples in March 2009. Laboratory analysts knew the dates of tooth collection but did not know sex, location, or individual identity of duplicate teeth. Most samples (50 of 54) were longitudinally sectioned, dyed with
Giemsa stain, and evaluated for cementum line patterns. Ages of four teeth were determined to $1 \mathrm{yr}$ by inspection of morphology without sectioning (Matson 1981). Ages of all other teeth were determined by G. Matson according to a standard model for bighorn (Ovis canadensis) and Dall sheep (Ovis dalli) developed by Matson (1981), and the teeth were classified into one of three certainty categories (A, B, or C), based on how closely the sample matched that model, including the clarity of cementum lines, morphology, and estimated age. Samples that closely matched the standard model were given a certainty score of $\mathrm{A}$ and an estimated age. Samples that did not match the model perfectly (certainty score B) or matched only poorly (certainty score C) were also given age ranges. Methodological repeatability was assessed with pairs of teeth from five individuals. Matson's Laboratory also provided cementum data from an additional 26 individual mouflon of unknown sex collected in June 1994 from Kahuku (O'Gara 1994).

\section{Data Analysis}

For animals whose ages were estimated as $\leq 3$ yr by dentition, we determined if histological quality of teeth among cementum certainty scores affected agreement of cementum and dentition age estimates using a one-way analysis of variance (ANOVA) and Fisher's LSD post-hoc tests (Sokal and Rohlf 1995). We excluded the four teeth estimated to be $\leq 1$ yr based on morphology because cementum lines were not used for determining age. We then compared age-determining techniques by calculating the percentage of estimates that agreed. We also calculated the percentage of age estimates from dentition that fell within the estimated age range from cementum for teeth with certainty scores of B and C. In addition, we compared estimates from both methods within each certainty score category using paired $t$-tests and Pearson's correlation coefficient $r$ (Sokal and Rohlf 1995). All statistical tests were performed with SAS (SAS Institute 1999), and $P$-values $<.05$ were considered significant.

We constructed age distributions from 
cementum estimates and log-linear models using the Marquardt iterative method to estimate annual survival (PROC NLIN [SAS Institute 1999]). The model equation took the form $Y=\exp \left(B_{0}+\left[B_{1} * X\right)\right]$, where $X$ was the age category and $Y$ was the predicted number of mouflon in category $X$. Although it was necessary to estimate a model intercept $\left(B_{0}\right)$, this was not biologically meaningful by itself. Of primary interest, we interpreted the exponent of $B_{1}$ as the estimate of annual survival, which approximated a monotonic decline in an age frequency, and $95 \%$ confidence intervals (CIs) of survival were interpreted as the exponents of $95 \%$ CIs of $B_{1}$. We compared $B_{1}$ values and their associated 95\% CIs between the 1994 and the 20072008 samples to determine if age structure and annual survival had changed between those periods. The sex composition of the 49 sampled individuals included 41 ewes and eight rams, reflecting a greater female bias (84\% female) than the composition at large (73\% female [Stephens et al. 2008]). We did not attempt comparative analysis of sexes because of this sample size imbalance. Our approach for estimating survival was based on examination of a cross section of ages from the population during a short period of time (vertical approach) rather than following the fate of marked individuals over time (cohort approach). This type of approach is therefore more likely to reflect survival during the period of study rather than survival over time and may be affected by short-term events such as drought.

\section{RESULTS}

Cementum lines were present in teeth of mouflon from Mauna Loa, Hawai'i Island, but formation appeared to be indistinct, without regular layering relative to North American sheep (G. Matson, pers. comm.). Nonetheless, differential staining between dark and light cementum bands was fair. Matson's Laboratory estimated the ages of 54 teeth and assigned certainty scores to each as follows: A, 23; B, 19; and C, 12. There were discrepancies in determining the age of four of five tooth pairs from the same individuals, with a mean difference of $2.4 \mathrm{yr}$ and a maximum of $4 \mathrm{yr}$. However, those with higher certainty scores (A or B, $n=3$ pairs) matched or were only $1 \mathrm{yr}$ apart. For individuals with paired tooth samples that conflicted in age, we used the estimate with the highest certainty score (one of four cases), and when histology was the same, we used the greater age (three of four cases) for further analyses. Samples from O'Gara (1994) were given relatively high certainty scores (A: 9, B: 17).

Age estimates from cementum lines and dentition generally agreed, although they varied with cementum certainty score. For individuals estimated $\leq 3$ yr old by dentition $(n=35)$, samples with certainty score A had significantly lower discrepancies between techniques than samples with scores of $\mathrm{B}$ or $\mathrm{C}$ (ANOVA: $F=12.16$; $\mathrm{df}=2,32 ; P=0.0001$ [Table 1]). Discrepancies $>1 \mathrm{yr}$ were from teeth with certainty scores of B or C. Because certainty score affected the discrepancy be-

TABLE 1

Comparison of Discrepancies between Age Estimates (yr) from Tooth Cementum and Dentition for European

Mouflon Sheep from the Kahuku Unit of Hawai'i Volcanoes National Park, Mauna Loa, Hawai'i, 2007-2008

\begin{tabular}{lcccccc}
\hline \hline Certainty & $\begin{array}{c}n \\
\text { Score }\end{array}$ & $\begin{array}{c}\text { Mean } \\
\text { (Individuals) } \\
\text { (range) }\end{array}$ & $\begin{array}{c}\text { Agreement with } \\
\text { Agreement }\end{array}$ & $\begin{array}{c}\text { Cementum } \\
\text { Range }\end{array}$ & $\begin{array}{c}\text { Paired } \\
t \text {-Test }{ }^{a}\end{array}$ & $\begin{array}{c}\text { Pearson's } \\
r\end{array}$ \\
\hline A & 20 & $0.2^{b}(0-1)$ & $80 \%$ & - & $t=1.00 ; \mathrm{df}=19 ; P=.330$ & 0.844 \\
$\mathrm{~B}$ & 10 & $1.5(0-4)$ & $20 \%$ & $60 \%$ & $t=2.18 ; \mathrm{df}=9 ; P=.057$ & 0.508 \\
$\mathrm{C}$ & 5 & $1.8(0-3)$ & $20 \%$ & $40 \%$ & $t=3.09 ; \mathrm{df}=4 ; P=.037$ & 0.612 \\
\hline
\end{tabular}

Note: Data include only individuals that were determined to be $\leq 3 \mathrm{yr}$ of age based on dentition.

${ }^{a} P<0.05$ indicates a significant difference in age estimates between techniques.

${ }^{b}$ Significantly lower than other certainty classes (Fisher's LSD: $P s<0.05$ ). 


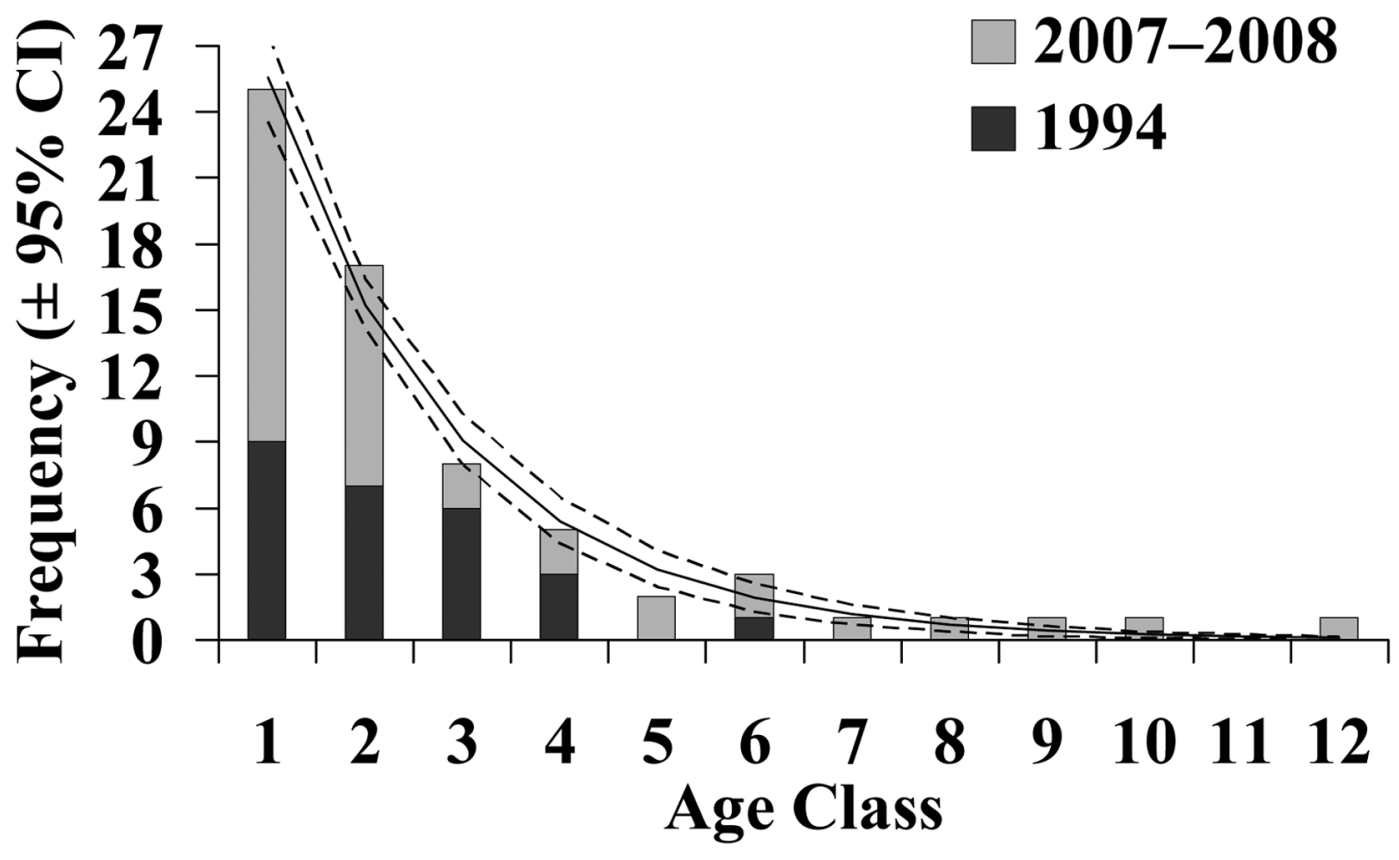

Figure 1. Age distributions of European mouflon sheep (bars represent samples from $1994[n=26]$ and 2007-2008 $[n=39]$ ) from tooth cementum annuli with certainty scores A and B. Predicted survival (solid line $\pm 95 \%$ CI dashed line envelope) was calculated from a $\log$-linear model, $Y=\exp \left(B_{0}+\left[B_{1} * X\right]\right)$, where exponent $B_{1}$ is the survival estimate.

tween age-determining methods, we compared these methods within each certainty class. Age estimates from cementum with certainty scores of A did not differ significantly from those from dentition and were well correlated (Table 1). Teeth with scores of B also did not differ, but those with scores of $\mathrm{C}$ differed, and both $\mathrm{B}$ and $\mathrm{C}$ scores were less correlated with dentition. Overall, the two methods provided exact age matches in $51 \%$ $(18 / 35)$ of the animals, and cementum estimates were higher in $40 \%$ and lower in $9 \%$ of the individuals, with an average difference of $0.8 \mathrm{yr}$ (range $0-4$ ). For individuals estimated $\geq 3$ yr old by dentition $(n=19)$, cementum age agreed in $74 \%$ of cases and cementum age range agreed in $89 \%$ of cases. We excluded scores of $\mathrm{C}$ from further analyses because age estimates from tooth cementum differed from those from dentition.

The combined cementum data produced a nearly monotonic decline in age frequency distribution (Figure 1). A log-linear model of the reduced data set for certainty scores of A produced a lower survival estimate, but with a wide and overlapping CI, than that of certainty scores of A and B combined, likely because of sparse data (Table 2). Using certainty scores of $\mathrm{A}$ and $\mathrm{B}$, we compared

\section{TABLE 2}

Survival Estimates and 95\% Confidence Intervals from Data Sets Fit with Log-Linear Model of European Mouflon Sheep in 1994 and 2007-2008

\begin{tabular}{lcc}
\hline \hline Data Set & $\begin{array}{c}\text { Survival } \\
\text { Estimate }\end{array}$ & $\begin{array}{c}95 \% \\
\text { Confidence } \\
\text { Interval }\end{array}$ \\
\hline $1994(n=26)$ & 0.655 & $0.570-0.753$ \\
$2007-2008(n=39)$ & 0.525 & $0.432-0.639$ \\
Certainty score A $(n=30)$ & 0.376 & $0.258-0.550$ \\
$\begin{array}{c}\text { Certainty score A and B } \\
(n=65)\end{array}$ & 0.596 & $0.554-0.642$ \\
\hline
\end{tabular}


survival between the 1994 and 2007-2008 samples. Estimated survival for 2007-2008 was lower, but CIs overlapped with that of 1994. We therefore pooled the data from both time periods to calculate an overall survival estimate. The log-linear model from data with certainty scores A and B produced an overall survival rate of 0.596 and $95 \%$ CI of 0.554-0.642 per annum for both time periods (Figure 1).

\section{DISCUSSION}

We found that determining age of mouflon by cementum and dentition provided similar results. Estimates of age from tooth eruption and wear have also been compared with those from cementum annuli in elk (Cervus elaphus) from Colorado (Keiss et al. 1969) and Alberta, Canada (Rosatte et al. 2007), with various results; however, distinct cementum line formation is likely in those strong temperate climates. We found no other studies from tropical environments that compared age estimates from tooth eruption or wear with those from cementum annuli in ungulates. In our samples, cementum age estimates were often higher than those from dentition. Also, teeth given higher certainty scores produced better concordance between age-determining methods, reinforcing the importance of collecting a sufficient number of samples to compensate for samples of lower quality that may be excluded from analyses, which comprised approximately $22 \%$ of teeth in our study. The effect of diet on cementum formation in vivo under tropical environmental conditions may cause some tooth samples to have unclear histology.

The tooth cementum method appears to be as good as or better than dentition because it is not limited to ages $\leq 3 \mathrm{yr}$. It also offers more specific age estimates than morphological characteristics of horn and facial patterns, particularly for ewes (Garel et al. 2005, 2006). In rare circumstances, uniform tooth wear and wide spacing in dentition of old ewes may resemble the deciduous teeth of lambs (Kammlade 1947). However, body size, hoof condition, and pelage may be used to further discriminate these cases. Old ewes are gener- ally larger, often have worn or damaged hooves, and have more extensive white facial markings (Garel et al. 2005, 2006). The true age of study animals could not be known without a sample of individuals marked as lambs. Further validation of the cementum method should be pursued in tropical environments with individuals of known age (e.g., Wittwer-Backofen et al. 2004).

The relatively indistinct patterning of cementum line formation in Kahuku mouflon is surprising given the distinct lines found in teeth of feral cats (Felis catus) from Mauna Kea, which is approximately $50 \mathrm{~km}$ away in a similar subalpine environment (Danner et al. 2010). Brokx (1972) also found indistinct cementum patterns in Venezuelan white-tailed deer (Odocoileus virginianus gymnotis). These differences in patterning may be related to more seasonal variability in diets of tropical carnivores than those of herbivores. Lieberman (1993) found that in captive goats cementum lines were formed by two factors associated with diet. First, altering the physical composition of food affected occlusal strain and thus altered collagen fiber orientation. Second, nutrition affected tooth growth rate: it was positively related to cementum band width and negatively related to mineral density. Therefore, a relatively constant diet, causing consistent occlusal strain and growth rate, may result in indistinct cementum line formation.

It would be more likely for mouflon at Kahuku to receive a seasonally consistent diet if they consumed a greater proportion of perennial shrubs than annual grasses or other seasonal plants. However, O'Gara (1994) found that Kahuku mouflon in June fed primarily on grasses and sedges, with shrubs, trees, and forbs composing $<28 \%$ of rumen volume. At some locations, $\geq 94 \%$ of rumen volume contained only grasses and sedges. In another mouflon population on Hawai'i Island, Giffin (1982) found that trees, primarily māmane (Sophora chrysophylla), and shrubs accounted for $>54 \%$ of mouflon rumen volume on Mauna Kea, and grasses accounted for only $34 \%$. Therefore, we would expect some differences in cementum formation between mouflon populations and 
locations on Hawai'i Island. Mouflon were present throughout diverse habitats at $\mathrm{Ka}$ huku but maintained home ranges of $<300$ ha (U.S. Geological Survey, unpubl. data). This probably limited the variety of forage available to individuals but may have resulted in strong differences in diet between individuals, which could have affected our results at the population level through differences in cementum formation.

Indistinct cementum layering may also be related to a lack of seasonality in grasses, contributing to a seasonally consistent diet for mouflon. In nondrought periods, some green sward is available throughout the year in most places at Kahuku (L. Pratt, U.S. Geological Survey, pers. comm.), which may be related to peak annual rainfall during the months of November-January that would otherwise cause a cessation in growing season. No information is available about seasonality in mouflon diet in Hawaili, but in Moravia during autumn, mouflon consumed a wide variety of seeds and woody broadleaf and coniferous vegetation (Heroldová et al. 2007). Mouflon on Tenerife, Canary Islands, consumed a wide variety of woody plants and shrubs in autumn (Rodríguez Luengo et al. 1988, Rodríguez Luengo and Piñero 1991); however, mouflon on Île Haute, Kerguélen Islands, primarily consumed several species of grasses and herbaceous plants during the severe austral winter (Chapuis et al. 2001).

Although cementum line formation in many temperate-zone species is thought to be annual (Grue and Jensen 1979), tropical species have been found to deposit one line in areas with unimodal rainfall (Spinage 1976) and two lines in areas with bimodal rainfall (Spinage 1967, Grimsdell 1973, Sinclair 1974, Kay and Cant 1988). Seasonality in rainfall in the Kahuku study area is unimodal, with less than half the monthly amount in May-June as in November-January; however, a closely controlled longitudinal study is needed to determine the precise effect of this precipitation pattern on cementum development.

We found limited evidence that Kahuku mouflon survival had declined from 1994 to
2007-2008, although the sample size from 1994 was lower. Our estimated annual survival rate of 0.596 is lower than that of mouflon in other regions of the world but may be accurate for a heavily controlled population that is also subject to predation by feral dogs (Canis familiaris) (U.S. Geological Survey, unpubl. data) and verminous pneumonia caused by lungworm (Muellerius capillaris) (O'Gara 1994; J. Powers, DVM, National Park Service, pers. comm.). Mouflon in France, which are subject to outbreaks of keratoconjunctivitis, had an estimated range of annual survival of $0.736-1.00$ during nonepizootic periods (Cransac et al. 1997, Dupuis et al. 2002, King and Brooks 2003). This difference, and the likelihood of less-distinct cementum patterning in tropical environments, suggests that any potential bias in our estimate using the cementum method is most likely negative. Regardless of potential biases, we believe that the cementum method was validated by our comparison with dentition and provides a useful relative index of mouflon age structure and survival for similar tropical latitudes and environments, despite the potential effects of relatively constant diet.

\section{ACKNOWLEDGMENTS}

We thank H. Hoshide, D. Hu, R. Loh, and J. T. Tunison for facilitation and guidance; J. Faford, D. Pacheco, and J. Branco for field assistance; and two reviewers for helpful comments. We also acknowledge the legacy of Bart O'Gara, the first wildlife biologist to study the Kahuku mouflon.

\section{Literature Cited}

Brokx, P. A. 1972. Age determination of Venezuelan white-tailed deer. J. Wildl. Manage. 36:1060-1067.

Chapuis, J. L., P. Boussès, and G. Barnaud. 1994. Alien mammals, impact and management in the French sub-Antarctic islands. Biol. Conserv. 67:97-104.

Chapuis, J. L., P. Boussès, B. Pisanu, and D. Réale. 2001. Comparative rumen and fecal diet microhistological determinations 
of European mouflon. J. Range Manage. 54:239-242.

Cransac, N., A. J. M. Hewison, J. M. Gaillard, J. M. Cugnasse, and M. L. Maublanc. 1997. Patterns of mouflon (Ovis gmelini) survival under moderate environmental conditions: Effects of sex, age and epizootics. Can. J. Zool. 75:1867-1875.

Danner, R. M., C. Farmer, S. C. Hess, R. M. Stephens, and P. C. Banko. 2010. Survival of feral cats, Felis catus (Carnivora: Felidae), on Mauna Kea, Hawai'i, based on tooth cementum lines. Pac. Sci. 64:381389.

Dupuis, J. A., J. Badia, M. Maublanc, and R. Bon. 2002. Survival and spatial fidelity of mouflons (Ovis gmelini): A Bayesian analysis of an age-dependent capture-recapture model. J. Agric. Biol. Environ. Stat. 7:277-298.

Eberhardt, L. L. 1985. Assessing the dynamics of wild populations. J. Wildl. Manage. 49:997-1012.

Gaillard, J. M., M. Festa-Bianchet, and N. G. Yoccoz. 1998. Population dynamics of large herbivores: Variable recruitment with constant adult survival. Trends Ecol. Evol. 13:58-63.

Garel, M., J. M. Cugnasse, A. J. M. Hewison, and D. Maillard. 2006. Errors in age determination of mouflon in the field. Wildl. Soc. Bull. 34:300-306.

Garel, M., J. M. Cugnasse, and D. Maillard. 2005. Reliability of mouflon aging using morphological characteristics from observations in the field. Wildl. Biol. 11:229235.

Giffin, J. G. 1982. Ecology of the mouflon sheep on Mauna Kea. Hawai'i Department of Land and Natural Resources, Honolulu.

Grimsdell, J. J. R. 1973. Age determination of the African buffalo, Syncerus caffer Sparrman. East Afr. Wildl. J. 11:31-53.

Grue, H., and B. Jensen. 1979. Review of formation of incremental lines in tooth cementum of terrestrial mammals. Dan. Rev. Game Biol. 11:1-48.

Hackett, E. J., D. C. Guynn, and H. A. Jacobson. 1979. Differences in age structure produced by two aging techniques. Pages 25-29 in R. W. Dimmick, ed. Proc.
Annu. Conf. Southeast. Assoc. Fish Wildl. Agencies. Hot Springs, Arkansas.

Hamlin, K. L., D. F. Pac, C. A. Sime, R. M. DeSimone, and G. L. Dusek. 2000. Evaluating the accuracy of ages obtained by two methods for Montana ungulates. J. Wildl. Manage. 64:441-449.

Heroldová, M., M. Homolka, J. Kamler, P. Koubek, and P. Forejtek. 2007. Foraging strategy of mouflon during the hunting season as related to food supply. Acta Vet. Brno 76:195-202.

Hess, S., B. Kawakami Jr., D. Okita, and K. Medeiros. 2006. A preliminary assessment of mouflon abundance at the Kahuku Unit of Hawaii Volcanoes National Park. U.S. Geological Survey Open File Report OF 2006-1193. U.S. Geological Survey, Reston, Virginia.

Kammlade, W. G., ed. 1947. Sheep science. J. B. Lippincott Co., Philadelphia.

Kay, R. F., and J. G. H. Cant. 1988. Age assessment using cementum annulus counts and tooth wear in a free-ranging population of Macaca mulatta. Am. J. Primatol. 15:1-15.

Keiss, R. E. 1969. Comparison of eruptionwear patterns and cementum annuli as age criteria in elk. J. Wildl. Manage. 33:175180.

King, R., and S. P. Brooks. 2003. Survival and spatial fidelity of mouflons: The effect of location, age, and sex. J. Agric. Biol. Environ. Stat. 8:486-513.

Laws, R. 1952. A new method of age determination for mammals. Nature (Lond.) 169:972-973.

Lieberman, D. E. 1993. Life history variables preserved in dental cementum microstructure. Science (Washington, D.C.) 261:1162-1164.

Mason, D. R. 1984. Dentition and age determination of the warthog Phacochoerus aethiopicus in Zululand, South Africa. Koedoe 27:79-119.

Matson, G. M. 1981. Workbook for cementum analysis. Matson's Laboratory, Milltown, Montana.

Montana Veterinary Research Laboratory. 1936. Judging the age of sheep by their teeth. Montana Experiment Station Circu- 
lar No. 149. Montana State College, Bozeman.

Nogales, M., J. L. Rodríguez Luengo, and P. Marrero. 2006. Ecological effects and distribution of invasive non-native mammals on the Canary Islands. Mammal Rev. $36: 49-65$.

O'Gara, B. W. 1994. Report to trustees of the Damon Estate concerning mouflon on the Kahuku Ranch. Manuscript at the K. Ross Toole Archives, Mansfield Library, University of Montana, Missoula.

Rodríguez Luengo, J. L., and J. C. Piñero. 1991. Autumn diet of the Corsica mouflon Ovis ammon musimon Shreber 1782 on Tenerife, Canary Islands. Pages 137-140 in B. Bobek, K. Perzanowski, and W. L. Regelin, eds. Trans. 18th IUGB (International Union of Game Biologists) Congress. Swiat Press, Krakow, Poland.

Rodríguez Luengo, J. L., J. C. Rodríguez, and M. T. Ramos. 1988. Autumn diet selectivity of the Corsica mouflon (Ovis ammon musimon Shreber, 1782) on Tenerife (Canary Islands). Mammalia 52:475481.

Rosatte, R., A. Silver, M. Gibson, B. Chisholm, and N. Cool. 2007. Correlation between age estimates for elk, Cervus elaphus, using tooth wear/eruption patterns and counts of annuli in tooth cementum. Can. Field-Nat. 121:214-215.

SAS Institute. 1999. SAS/STAT user's guide. Version 8. SAS Institute, Cary, North Carolina.

Sinclair, A. R. E. 1974. The natural regulation of buffalo populations in East Africa. East Afr. Wildl. J. 12:169-183.

Sokal, R. R., and F. J. Rohlf. 1995. Biometry: The principles and practice of statistics in biological research. Freeman \& Co., New York.

Spinage, C. A. 1967. Aging the Uganda defassa waterbuck Kobus defassa ugandae Neumann. East Afr. Wildl. J. 5:1-17. 1976. Incremental cementum lines in the teeth of tropical African mammals. J. Zool. (Lond.) 178:117-131.

Stephens, R. M., S. C. Hess, and B. Kawakami Jr. 2008. Controlling mouflon sheep at the Kahuku Unit of Hawai'i Volcanoes National Park. Proc. Vertebr. Pest Conf. 23:304-309.

Tomich, P. Q. 1986. Mammals in Hawai'i. Bishop Museum Press, Honolulu.

Wittwer-Backofen, U., J. Gampe, and J. W. Vaupel. 2004. Tooth cementum annulation for age estimation: Results from a large known-age validation study. Am. J. Phys. Anthropol. 123:119-129. 
